\title{
Influence of chronic pain on cognitive performance in elderly caregivers: a longitudinal study
}

\author{
Influência da dor crônica no desempenho cognitivo em cuidadores idosos: estudo longitudinal \\ Influencia del dolor crónico en el desempeño cognitivo en cuidadores ancianos: un estudio longitudinal
}

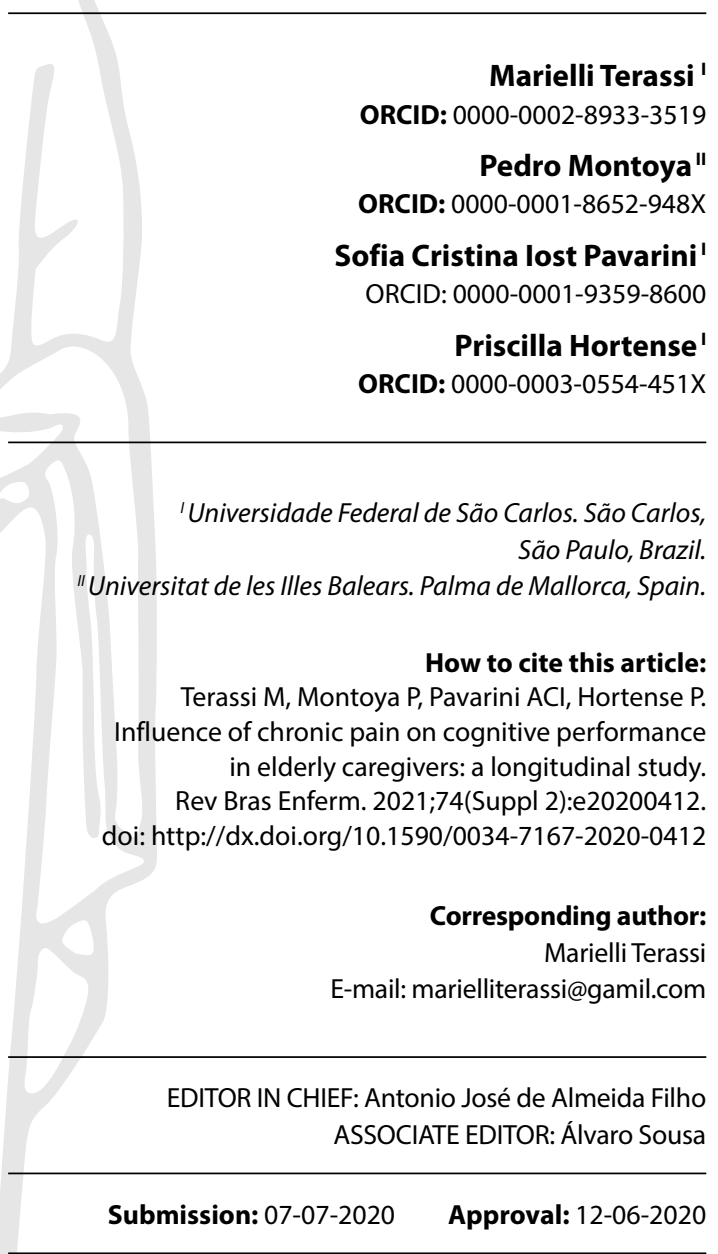

\begin{abstract}
Objective: to compare cognitive performance of elderly caregivers with and without chronic pain over four years and verify the effect of pain intensity on cognitive performance of elderly caregivers with chronic pain. Method: a longitudinal study with data collected in 2014 and 2018. Community-dwelling elderly caregivers of a Brazilian city participated in the study. Cognition was assessed using the Addenbrooke's Cognitive Examination instrument. Pain was assessed by an 11-point scale. For data analysis, a mixed linear model and ANCOVA with a 5\% significance level were used. Results: they were divided into two groups. A cognitive decline over four years was found in elderly people with pain $(p=0.02 ; 95 \% \mathrm{Cl}=0.32-4.25)$, while those without pain did not show a significant change. Conclusion: the results show that elderly caregivers with pain had a worse cognitive performance, but when comparing groups with the ANCOVA test for intergroup analysis, there was no difference in cognitive performance. Descriptors: Elderly; Caregivers; Cognition; Chronic Pain; Public Health.
\end{abstract}

\section{RESUMO}

Objetivo: comparar o desempenho cognitivo de cuidadores idosos com e sem dor crônica ao longo de quatro anos e verificar o efeito da intensidade da dor no desempenho cognitivo de cuidadores idosos com dor crônica. Método: estudo longitudinal com dados coletados em 2014 e 2018. Participaram do estudo cuidadores idosos residentes na comunidade de um município brasileiro. A cognição foi avaliada usando o Addenbrooke's Cognitive Examination. A dor foi avaliada por uma escala de 11 pontos. Para a análise dos dados, foi utilizado um modelo linear misto e ANCOVA com nível de significância de $5 \%$. Resultados: foram divididos em dois grupos. Declínio cognitivo ao longo de quatro anos foi encontrado em idosos com dor ( $p=0,02 ; I C 95 \%=0,32-4,25)$, enquanto aqueles sem dor não apresentaram alteração significativa. Conclusão: os resultados mostram que os cuidadores idosos com dor tiveram pior desempenho cognitivo, mas ao comparar os grupos com o teste ANCOVA para análise intergrupos, não houve diferença no desempenho cognitivo. Descritores: Idoso; Cuidadores; Cognição; Dor Crônica; Saúde Pública.

\section{RESUMEN}

Objetivo: comparar el desempeño cognitivo de los cuidadores ancianos con y sin dolor crónico durante cuatro años y verificar el efecto de la intensidad del dolor sobre el desempeño cognitivo de los cuidadores ancianos con dolor crónico. Método: estudio longitudinal con datos recolectados en 2014 y 2018. Los participantes del estudio fueron cuidadores ancianos residentes en la comunidad de un municipio brasileño. La cognición se evaluó mediante el instrumento Addenbrooke's Cognitive Examination. El dolor se evaluó mediante una escala de 11 puntos. Para el análisis de datos se utilizó un modelo lineal mixto y ANCOVA con un nivel de significancia del $5 \%$. Resultados: se dividieron en dos grupos. Se encontró deterioro cognitivo durante cuatro años e ancianos con dolor ( $p=0,02$; IC $95 \%=0,32-4,25)$, mientras que aquellos sin dolor no mostraron cambios significativos. Conclusión: los resultados muestran que los cuidadores de ancianos con dolor tuvieron peor desempeño cognitivo, pero al comparar grupos con la prueba ANCOVA para análisis intergrupal, no hubo diferencia en el desempeño cognitivo.

Descriptores: Anciano; Cuidadores; Cognición; Dolor Crónico; Salud Pública. 


\section{INTRODUCTION}

The number of elderly people who care for another elderly at the same home has been increasing in recent years due to aging associated with increased life expectancy ${ }^{(1-3)}$. With increasing age, it is possible to observe changes in the epidemiological profile with the predominance of chronic non-communicable diseases. Chronic pain is a problem that represents one of the main complaints and searches for health services care by elderly people ${ }^{(4-7)}$. The International Association for the Study of Pain (IASP) recently updated the definition of pain: "An unpleasant sensory and emotional experience associated with, or resembling that associated with, actual or potential tissue damage"(8).

The consequences of pain in elderly people's lives include biopsychosocial impairments, such as reduced mobility, increased falls, loss of autonomy, decreased performance in daily activities. There is also an increasing prevalence of depressive symptoms, anxiety disorders, in addition to negative impacts on social interaction, with emphasis on family relationship ${ }^{(4,6,9)}$. A study of elderly people in Poland found that demand for health services was greater among participants with chronic pain, representing $42 \%$ of the sample; $54.6 \%$ of the participants in this group reported at least one medical appointment in the last month ${ }^{\left({ }^{(10)} \text {. It }\right.}$ is noteworthy that these losses can be greater in elderly caregivers, and the physical burden of taking care of another elderly can predispose to the emergence of chronic pain, although there are still few studies that assess pain in this population ${ }^{(11)}$.

Associated with negative impacts of pain, studies show that individuals with chronic pain may have worse cognitive performance over the years when compared to individuals without pain, but the authors emphasize that interpretation need caution, highlighting the need for new research ${ }^{(12-13)}$. A study developed with elderly people population of a community showed a result of an inversely proportional association between pain intensity and the score in cognitive attention tests ${ }^{(14)}$. A longitudinal study also with elderly population of a community identified that participants with persistent pain showed an increased risk of developing memory deficit when compared to the painless group ${ }^{(15)}$.

Pain and cognition share elements among themselves, such as components of learning, recall, memories of experiences, and decision-making ${ }^{(16)}$. Some studies describe that chronic pain is also a stimulus that can be able to affect the dynamic state of the brain and interfere in the cognitive process, causing deficits in memory, concentration, and attention, in addition to reduced response time ${ }^{(16-17)}$.

Some studies define the negative influence of chronic pain on attention, assuming that stimuli during the pain process can disrupt the attentional control mechanisms, thus developing an impaired performance ${ }^{(18)}$. A systematic review shows that deficit of care has been demonstrated in studies with different etiologies of chronic pain, as in particular with fibromyalgia, chronic low back pain and groups with heterogeneous reports of pain in different age groups ${ }^{(16)}$.

Up to now, there are no longitudinal studies on the effects of chronic pain on elderly caregivers' cognition. In an attempt to respond to the scarcity of information, we formulated the following research questions: do elderly caregivers with chronic pain have worse cognitive performance over time when compared to elderly caregivers without pain? What variables could relate to the worst performance of cognition? Does pain intensity relate to worsening cognitive performance? It is believed that the results found can bring contributions on the theme of elderly caregivers and on the relationship between chronic pain and cognitive performance, enabling the creation of preventive measures and interventions that offer necessary care for this population.

\section{OBJECTIVE}

To compare cognitive performance of elderly caregivers with and without chronic pain over four years and verify the effect of pain intensity on cognitive performance of elderly caregivers with chronic pain.

\section{METHOD}

\section{Ethical procedures}

The current study had a favorable opinion of the Municipal Health Department and the Ethics Committee on Research with Human Beings (CAAE (Certificado de Apresentação para Apreciação Ética - Certificate of Presentation for Ethical Consideration)) for data collection conducted in 2014 and for the 2018 collection. All the elderly people who agreed to participate in the study signed the Informed Consent Form. All ethical precepts determined by Resolution 466/12 of the Brazilian National Health Council (Conselho Nacional de Saúde) of the Ministry of Health were met.

\section{Study design, period, and place}

This is a quantitative, observational, prospective and longitudinal research, guided by the STROBE tool, developed in a city in the countryside of São Paulo, Brazil with data collected in 2014 and 2018.

\section{Study population and data collection procedures}

People aged 60 years and over who informally took care of another elderly person in the same household, living in the urban areas and registered in Family Health Units (FHUs) participated in the study.

\section{Baseline assessment}

The first assessment took place in 2014. All participants were identified through lists provided by FHUs, with names and addresses of all elderly people who lived with at least one other elderly person in the same household. To identify elderly caregivers, we used assessment questionnaires on performance of basic activities of daily living ${ }^{(19)}$ and instrumental activities of daily living $^{(20)}$. Elderly people with the best performance in the score by summing up both instruments were caregivers while elderly people with the lowest score were the ones who received care. All residences registered in the FHU where two elderly people or more lived were visited by the research members.

Basic Activities of Daily Living (ADL) assess activities related to the ability to eat, taking a bath, getting dressed, getting ready, mobilizing, and going to the toilet. Assessment is performed by 
summing up the scores that can vary from zero to six. Individuals are independent for ADL when the sum is equal to 6 points; 4 points shows moderate dependence and 2 points or less demonstrates total dependence ${ }^{(19)}$.

Instrumental Activities of Daily Living (IADL) assess the performance of more complex tasks such as using the telephone, going shopping, preparing meals, doing household chores, using means of transportation, taking medications, and handling money. The total score of the scale can vary from 7 to 21 , when 7 denotes total dependence, 8 to 20 , partial dependence, and 21 , independence ${ }^{(20)}$.

\section{First assessment}

Elderly people aged 60 years or more, being registered in a FHU of the municipality and performing some informal caregiving activity to another elderly at home identified according to basic and instrumental activities of daily living scales were included.

Elderly people who changed their address, who were not found in their homes after three attempts at alternate periods and elderly people who were equally independent, i.e., there was no caregiver in the residence were excluded. Thus, 266 elderly caregivers were part of the first stage.

\section{Second assessment}

The reassessment took place in 2018 where all homes were visited again, and all elderly people would be included. To avoid bias of results, the exclusion criteria established excluded participants who had a change in pain over the four years, i.e., the participant who reported pain in 2014 and did not report in 2018 (n=9), and those who did not report pain in 2014 and reported in $2018(n=14)$. Moreover, we excluded elderly caregivers who showed speech impairment or very important cognitive decline in which the interviewer could not perform the assessment $(n=9)$. However, there were some losses due to various causes such as death ( $n=32)$, three unsuccessful contact attempts at different days and times $(n=16)$, change of address where the interviewer could not obtain information about the new home $(n=36)$, and refusals $(n=46)$. Figure 1 shows in detail the participants excluded and included in the studies.

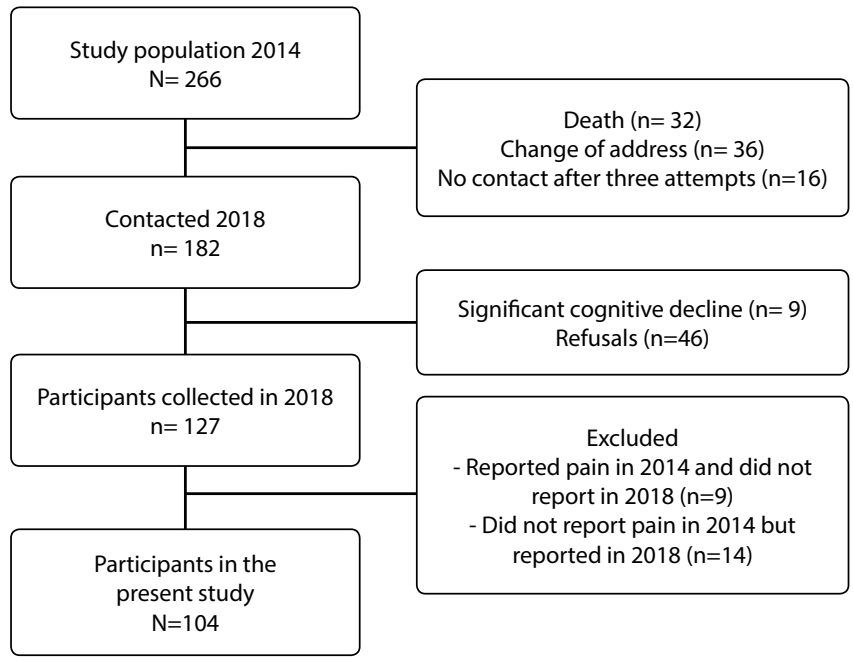

Figure 1 - Diagram of participants included and excluded in the 2018 sample

\section{Investigated variables}

- Predictor variable: chronic pain. In this study, we considered chronic pain as the pain lasting 6 months or more, continuous or recurrent ${ }^{(21)}$, and intensity was assessed by the numerical 11 point-scale (0-10), being 0 no pain and 10 worst imaginable pain.

- Outcome variable: cognitive performance. This variable was assessed by the Addenbrooke's Cognitive Examination Revised (ACE-R). The original version of the Addenbrooke Cognitive Exam (ACE) was developed at the Addenbrooke hospital in the city of Cambridge and validated in Brazil by Carvalho and Caramelli ${ }^{(22)}$. A scale assesses five cognitive domains: attention and orientation, memory, verbal fluency, language, and visuospatial ability. The ACE-R includes in its structure the Mini Mental State Examination (MMSE), the ClockDrawing Test (CDT) and two verbal fluency tests, category letter "P" and category"Animals". The overall ACE-R score ranges from 0 to 100 points, distributed between the six domains: orientation/attention (18 points), memory ( 26 points), verbal fluency (14 points), language (26 points), and visuospatial skills (16 points) ${ }^{(22)}$.

- Covariates: sociodemographic characteristics (sex, age and education), number of medications and number of comorbidities, hours of care, depressive symptoms, and perceived stress. This information was obtained through a questionnaire prepared by the researchers.

Overload was assessed by the Zarit Overload Inventory with 22 Likert-type questions. The sum of the questions can vary from 0 to 88 points $^{(23)}$.

Depressive symptoms were measured by the Geriatric Depression Scale (GDS-15), which aims to track depressive symptoms in the elderly people. It is composed of 15 questions, with dichotomous alternatives, "yes" or "no", and scores can vary from 0 to 15 points ${ }^{(24)}$.

The perceived stress was assessed by the Perceived Stress Scale (PSS), composed of 14 questions in which each item shows answer options ranging from 0 to $4(0=$ never, $1=$ almost never, 2 = sometimes, 3 = almost always, $4=$ always). The total scale can range from 0 to 56 . The scale does not present a cut-off score. The higher the score in the instrument, the higher the stress level(25).

\section{Data analysis}

For analysis, a database was created in the Excel 2010 software with double data entry. After the double entry validation, the data were exported to the Software SAS system for Windows (9.2).

In comparison tests of independent samples (comparison of sociodemographic characteristics, health and cognitive assessment between groups) at baseline, we used Student's t test and chi-square test. For comparisons involving groups and times in relation to ACE-R domains, the linear regression model with mixed effects (random and fixed effects) was proposed. For comparisons between the groups in relation to Delta time (before-after), we chose analysis of covariance (ANCOVA). ANCOVA was used to verify, in participants with chronic pain, the interference of pain intensity in cognitive results. All models were adjusted according to sex, age, educational level, number of medications, number of comorbidities, hours of care, stress, and depressive symptoms. For all statistical tests, a 5\% significance level was adopted. 


\section{RESULTS}

For this study, only elderly people who reported chronic pain in both assessments were selected as well as those who did not report chronic pain in both assessments. Thus, 104 elderly caregivers participated in this study. Of the participants selected for the study $(n=266)$ in 2014, 139 were not interviewed again in 2018 due to at least one of the following conditions: death, refusal, change of address, inability to answer the questionnaires or not found after three attempts in days and alternate times.

Between caregivers who answered and those who did not answer the second assessment, there were no significant differences regarding age, education, number of medications prescribed, number of comorbidities, stress, care burden, and chronic pain intensity. Among the unassessed elderly, slightly more than $50 \%$ were from the group with chronic pain in 2014.

The sociodemographic and health characteristics of the 104 participants at baseline were divided into two groups: with chronic pain $(n=73)$ and without pain $(n=31)$. We identified that the group with chronic pain had a higher number of female participants. The group with chronic pain reported daily use of a larger number of medications as well as a higher self-report of comorbidities. Additionally, we identified higher scores on stress and depressive symptoms between the groups in these variables (Table 1).

As for characteristics of care (daily hours of care and who provides the care), the groups did not show statistical differences. Care is provided to the spouse $(63 \%$ in the group with chronic pain and $96.7 \%$ in the group without pain). The daily time caregivers perform care was also similar between groups, with an average of approximately 5.7 hours for both (Table 1).

Longitudinal intragroup comparisons were performed using the mixed-effect linear regression model, noting statistical differences in the total score and memory domain in the group with chronic pain, showing a deterioration in cognitive performance of participants in this group over the course of the study. We observed worse performance of verbal fluency in the group without pain (Table 2). None of the adjusted variables in the model showed to be associated with the results.

We identified that there is no evidence that the group with chronic pain had greater change in cognitive performance over time, when compared to the group without pain in the ANCOVA analyzes of intergroup comparison of before-after differences in domains and total score of the ACE-R (Table 3).
Table 1 - Comparison of sociodemographic variables and health characteristics between the groups of caregivers with chronic pain and without pain at baseline, São Carlos, São Paulo, Brazil, 2014

\begin{tabular}{|c|c|c|c|c|}
\hline Variables & $\begin{array}{c}\text { Chronic pain } \\
\quad(n=73)\end{array}$ & $\begin{array}{c}\text { Without pain } \\
(n=31)\end{array}$ & $\begin{array}{c}\text { Total } \\
(n=104)\end{array}$ & $p$ value \\
\hline \multicolumn{5}{|l|}{ Sex } \\
\hline Female & $83.6 \%$ & $61,3 \%$ & $76.9 \%$ & \multirow{2}{*}{0.014} \\
\hline Male & $16.4 \%$ & $38.7 \%$ & $23.1 \%$ & \\
\hline Age (mean, SD) & $67.7( \pm 5.55)$ & $69.7( \pm 6.06)$ & $68.3( \pm 5.7)$ & 0.995 \\
\hline Educational level (mean, SD) & $3.0( \pm 2.7)$ & $3.1( \pm 3.3)$ & $3.0( \pm 2.9)$ & 0.798 \\
\hline Number of medications (mean, SD) & $3.6( \pm 2.3)$ & $1.7( \pm 1.5)$ & $3.0( \pm 2.2)$ & $<0.001$ \\
\hline Number of comorbidities (mean, SD) & $6.0( \pm 3.2)$ & $2.7( \pm 1.8)$ & $5.0( \pm 3.2)$ & $<0.001$ \\
\hline Care burden (continuous) (mean, SD) & $20.9( \pm 16.0)$ & $15.5( \pm 11.6)$ & $19.3( \pm 14.9)$ & 0.096 \\
\hline Stress perceived (mean, SD) & $21.8( \pm 10.8)$ & $12.9( \pm 8.0)$ & $19.5( \pm 10.6)$ & $<0.001$ \\
\hline \multicolumn{5}{|l|}{ Depressive symptoms } \\
\hline Presence & $37 \%$ & $3.3 \%$ & $27.2 \%$ & \multirow{2}{*}{$<0.000$} \\
\hline Absence & $63 \%$ & $96.7 \%$ & $72.8 \%$ & \\
\hline \multicolumn{5}{|l|}{ ACE-R domains (mean, SD) } \\
\hline Attention/orientation & $13.5( \pm 2.37)$ & $13.5( \pm 3.04)$ & $13.5( \pm 2.5)$ & 0.954 \\
\hline Memory & $14.6( \pm 5.79)$ & $13.9( \pm 6.4)$ & $14.4( \pm 5.9)$ & 0.576 \\
\hline Language & $18.3( \pm 4.82)$ & $17.4( \pm 5.75$ & $18.0( \pm 5.1)$ & 0.328 \\
\hline Verbal fluency & $5.7( \pm 2.93)$ & $6.3( \pm 2.93)$ & $5.9( \pm 2.8)$ & 0.326 \\
\hline Visuospatial skills & $10.3(3.55)$ & $9.4( \pm 3.61)$ & $10.0( \pm 3.5)$ & 0.614 \\
\hline Total score & $62.6( \pm 16.06)$ & $60.7( \pm 18.80)$ & $62.0( \pm 16.8)$ & 0.590 \\
\hline
\end{tabular}

Note: ACE-R - Addenbrooke's Cognitive Examination Revised; SD - Standard Deviation.

Table 2 - Intragroup comparison of cognitive performance in the groups with chronic pain and without pain through the Addenbrooke's Cognitive Examination Revised (domains and total score), São Carlos, São Paulo, Brazil, N=104, 2014 - 2018

\begin{tabular}{lcccccc}
\hline ACE-R domains & \multicolumn{3}{c}{$\begin{array}{c}\text { Chronic pain } \\
\mathbf{n = 7 3}\end{array}$} & & \multicolumn{3}{c}{$\begin{array}{c}\text { Without pain } \\
\mathbf{n = 3 1}\end{array}$} \\
& Estimate & $\mathbf{C l 9 5 \%}$ & $\boldsymbol{p}$ value & Estimate & $\mathbf{9 5 \%} \mathbf{C l}$ & $\boldsymbol{p}$ value \\
\hline Attention/orientation & 0.32 & $-0.15-0.78$ & 0.18 & 0.47 & $-0.25-0.19$ & 0.19 \\
Memory & 1.79 & $0.75-2.84$ & $<\mathbf{0 . 0 1}$ & 1.63 & $0.00-3.27$ & 0.05 \\
Verbal fluency & -0.08 & $-0.60-0.43$ & 0.75 & 0.93 & $0.13-1.73$ & $\mathbf{0 . 0 2}$ \\
Language & 0.04 & $-0.66-0.75$ & 0.91 & 0.37 & $-073-1.47$ & 0.51 \\
Visuospatial skills & 0.22 & $-0.29-0.72$ & 0.39 & -037 & $-1.15-0.42$ & 0.05 \\
Total score & 2.29 & $0.32-4.25$ & $\mathbf{0 . 0 2}$ & 3.03 & $-0.03-6.10$ & 0.05 \\
\hline
\end{tabular}

Note: ACE-R-Addenbrooke's Cognitive Examination Revised; $95 \%$ Cl - 95\% Confidence Interval; model adjusted for sex, age, education, number of medications, number of comorbidities, hours of care, stress, and depressive symptoms.

Table 3 - Comparison of differences between groups with chronic pain and without pain in relation to Delta time (2014-2018) of the Addenbrooke's Cognitive Examination Revised (domains and total score), São Carlos, São Paulo, Brazil, N=104, 2014 - 2018

\begin{tabular}{lccc}
\hline Comparison* & Estimate & $\mathbf{9 5 \%} \mathbf{C l}$ & P value \\
\hline ACER-R & 0.03 & $-4.23-4.30$ & 0.99 \\
Attention/orientation & -0.34 & $-1.33-0.65$ & 0.49 \\
Memory & -0.27 & $-2.59-2.05$ & 0.82 \\
Verbal fluency & 0.63 & $-0.48-1.74$ & 0.26 \\
Language & 0.59 & $-0.98-2.16$ & 0.46 \\
Visuospatial skills & -0.57 & $-1.72-0.58$ & 0.33
\end{tabular}

Note: ACE-R-Addenbrooke's Cognitive Examination Revised; $95 \%$ Cl-95\% Confidence Interval; ${ }^{*}$ Differences between groups: without pain - with pain; model adjusted by sex, age, educational level, number of medications, number of comorbidities, hours of care, stress, and depressive symptoms.

Table 4 - Analysis of the effect of pain intensity on Addenbrooke's Cognitive Examination Revised (domains and total score) of elderly caregivers with chronic pain, São Carlos, São Paulo, Brazil, N=104, 2014 - 2018

\begin{tabular}{lccc}
\hline Effect & Estimate & $\mathbf{9 5 \%} \mathbf{C l}$ & P value \\
\hline ACE-R & 0.03 & $-0.67-0.74$ & 0.93 \\
Attention/orientation & 0.07 & $-0.10-0.23$ & 0.44 \\
Memory & -0.17 & $-0.56-0.22$ & 0.38 \\
Verbal fluency & 0.10 & $-0.09-0.28$ & 0.28 \\
Language & 0.11 & $-0.17-0.38$ & 0.44 \\
Visuospatial skills & -0.07 & $-0.24-0.11$ & 0.46 \\
\hline
\end{tabular}

Note: $A C E-R$-Addenbrooke's Cognitive Examination Revised; $95 \%$ Cl-95\% Confidence Interval; model adjusted by sex, age, educational level, number of medications, number of comorbidities, hours of care, stress, and depressive symptoms 
To verify the relationship between pain intensity and cognitive performance through the domains and the total ACE-R score, a new ANCOVA test was performed and we identified that there is no evidence that change in pain intensity affected cognition (Table 4).

\section{DISCUSSION}

In the present study, we identified that community-dwelling elderly caregivers with chronic pain had a cognitive decline in the total score of the ACE-R and in the memory domain, compared to elderly caregivers without chronic pain (intra-group comparison). This change was not associated as well as none of the adjusted variables in the model. When comparing intergroup differences (before-after), we did not identify that there was a difference in worsening cognitive performance between the groups with chronic pain and without pain over four years. Similar data were found in a longitudinal study conducted in England with 6.515 individuals 50 years old and over that assessed cognitive performance using memory verbal fluency and processing speed tests. The results assessed using a linear regression analysis showed that over the four-year follow-up there were no statistical differences in cognitive tests between the groups with and without pain after adjusting analysis for confounding variables ${ }^{(26)}$.

However, the same study found statistical differences at baseline when comparing the group with chronic pain and without pain for memory ( $p<0.0001)$ and verbal fluency $(p<0.0001)$ domains ${ }^{(26)}$. We did not identify statistical differences between the groups for the ACE-R domains at baseline.

Some cross-sectional studies assessing the relationship between chronic pain and cognition also found differences showing that the group with pain performed worse on the tests assessed ${ }^{(12,14,27)}$. However, other research did not identify differences between groups in some cognitive domains ${ }^{(28-29)}$, showing the existence of conflicting data in literature.

Regarding memory assessment, a longitudinal study of 10.065 elderly people in the United States found that participants with persistent pain had a $9.2 \%$ (95\% Cl: $2.8-15.0)$ faster decline in memory score when compared to the group without pain. The results also showed that participants with chronic pain may be at increased risk of developing difficulties in managing their finances (95\% Cl. $0.8 \%-3.7 \%$ ) and medication use over a 10 -year period $(95 \%$ $\mathrm{Cl}$. $0.3 \%$ to $2.5 \%$ ) when compared to the group without pain ${ }^{(15)}$.

In this study, we observed a decline in memory score in the group with chronic pain. However, this did not mean that worsening was greater than in the group without pain. Thus, we believe this result can be related to the fact that memory is the cognitive function that more severely declines with age and is the main complaint of cognitive deficit in elderly people ${ }^{(30-31)}$. The profile of elderly participants of this study in which most of them have low educational level and low family income showed that they are related to a greater deficit in the memory domain ${ }^{(32-34)}$.

We emphasize that participants in this study are elderly caregivers, which may show peculiarities such as increased overload, higher stress rates, and depressive symptoms. Literature shows controversies about the influences of the act of caring on cognitive performance of informal caregivers and consequently the interference in the hours of care in this process. A longitudinal study conducted in Germany with elderly caregivers identified that caregiving favors cognitive performance but this influence depends on the pathology and dependence of the person who receives care ${ }^{(35)}$. Another longitudinal study conducted with caregivers of patients with Alzheimer's Disease (AD) found that participants had worse cognitive test scores ${ }^{(36)}$. Thus, we judge further details of the care provided and the characteristics of the person who receives care would be necessary to perform a deeper analysis of the results of the current study.

Pain intensity was not a factor associated with poor cognitive performance in this study. However, Veronese et al. (2018) ${ }^{(26)}$ reported that pain severity interfered with memory performance, and participants who reported severe pain had a stronger decline in memory performance $(-0.36$ points; $95 \% \mathrm{Cl}$ : $-0.68-0.04 ; \mathrm{p}=0.04)$ when compared to participants with mild and moderate pain.

We investigated elderly caregivers, a growing population in the Brazilian scenario and that studies with this population are still scarce. Literature presents results of studies that demonstrate the relationship between pain and cognition longitudinally, but studies that address this context in the population of caregivers could not be identified. Caregivers have peculiarities due to the act of caring. The respective variables were investigated in order to verify the relationship of cognition and pain in the context of care. The presented results reinforce the need for interventions including pain assessment and management in caregivers and actions that contribute to preserving cognitive and physical functionality.

\section{Study limitations}

We had losses in the second assessment ( $n=99)$, highlighting the predominance of participants with chronic pain. Another limitation is that more in-depth information on pain (time of chronic pain and pain interference in activities of daily living) should be collected at baseline data that could be relevant for further assessment of variable association with cognitive performance. The relationship between pain and cognitive decline is multifactorial so that studies with a larger number of variables are needed to analyze this association. New studies should consider variables such as opiate drug use and physical activity of caregivers as well as the type of pathology and care needed by the person who receives care.

\section{Contributions to nursing, health, or public policy}

The sample was composed of participants with low educational level and low family income data that differ from other international studies in which most of the population had higher educational level and better social conditions characteristics that may influence on cognitive performance ${ }^{(33-34)}$. Longitudinal studies with elderly caregivers are scarce in literature and it is necessary to identify the health profile of this population over time. To verify the influence of chronic pain on cognitive performance, multiprofessional actions need to be carried out in order to provide physical and psychological well-being for caregivers as well as the possibility of holistic assistance.

This study also allowed to know the sociodemographic profile of health conditions, care and chronic pain characteristics of elderly 
caregivers registered in FHUs followed-up over four years. We identified statistical differences at baseline for stress, depressive symptoms, number of medications and comorbidities variables, in which the group with pain had worse results.

\section{CONCLUSION}

We identified that elderly caregivers with chronic pain showed worse cognitive performance over four years in the total score of the ACE-R and in the memory domain; however, we did not identify such differences when we comparing the average differences in cognitive performance between the groups with chronic pain and without pain over the four years. Furthermore, we identified that this intensity of pain had no effect on cognitive performance in the group of caregivers with chronic pain.
Elderly caregivers were chosen as the target population of this study, since they represent a growing population in Brazil that shows physical, psychological, and cognitive comorbidities triggered by the act of caregiving, aggravated by the presence of chronic pain. In this way, nursing professionals, in conjunction with a multidisciplinary team, can contribute to identifying diseases and outline individualized interventions for each family.

\section{FUNDING}

This work was supported by the the Coordenação de Aperfeiçoamento de Pessoal de Nível Superior (CAPES), Fundação de Amparo à Pesquisa do Estado de São Paulo (FAPESP - n. 2018/23756-7); 2017/04129-9) and Conselho Nacional de Desenvolvimento Científico e Tecnólogico (CNPq) (n. 304068/2015-6).

\section{REFERENCES}

1. Pavarini SCI, Neri AL, Brigola AG, Ottaviani AC, Souza ÉN, Rossetti ES, et al. Elderly caregivers living in urban, rural and high social vulnerability contexts. Rev Esc Enferm USP. 2017;51. https://doi.org/10.1590/s1980-220x2016040103254

2. Terassi M, Rossetti ES, Gramani-Say K, Alexandre TS, Hortense P, Pavarini SCl, et al. Comparison of the cognitive performance of elderly caregivers with and without chronic pain. Rev Esc Enferm USP. 2017;51. https://doi.org/10.1590/S1980-220X2016023203260

3. Rossetti ES, Terassi M, Ottaviani AC, Santos-Orlandi AA, Pavarini SCl, Zazzetta MS. Frailty. depressive symptoms and overload of elderly caregivers in a context of high social vulnerability. Texto Contexto Enferm. 2018;27(3). https://doi.org/10.1590/0104-07072018003590016

4. Abdulla AN, Bone M, Elliott AM, Gaffin J, Jones D, et al. Guidance on the management of pain in older people. Age Ageing.2013;42(suppl1):i1-57. https://doi.org/10.1093/ageing/afs200

5. Duncan BB, Chor D, Aquino EML, Bensenor IM, Mill JG, Schmidt MI, et al. Doenças crônicas não transmissíveis no Brasil: prioridade para enfrentamento e investigação. Rev Saude Publica. 2012;46(suppl1):126-34. https://doi.org/10.1590/S0034-89102012000700017

6. Reid MC, Eccleston C, Pillemer K. Management of chronic pain in older adults. BMJ. 2015;350:h532. https://doi.org/https://doi.org/10.1136/ bmj.h532

7. Qiu Y, Li H , Yang Z, Liu Q, Wang K, Li R, et al. The prevalence and economic burden of pain on middle-aged and elderly Chinese people: results from the China health and retirement longitudinal study. BMC Health Serv Res. 2020; 20:600. https://doi.org/10.1186/ s12913-020-05461-6

8. Raja SN, Carr DB, Cohen M, Finnerup NB, Flor H, Gibson S, et al. The revised international association for the study of pain definition of pain: concepts, challenges and compromises. Pain.2020;161(9):1976-82. https://doi.org/10.1097/j.pain.0000000000001939

9. Bauer H, Emeny RT, Baumert J, Ladwig K-H. Resilience moderates the association between chronic pain and depressive symptoms in the elderly. Eur J Pain. 2016;20(8):1253-65. https://doi.org/10.1002/ejp.850

10. Kozak-Szkopek E, Broczek K, Slusarczyk P, Wieczorowska-Tobis K, Klich-Raczka A, Szybalska A, et al. Prevalence of chronic pain in the elderly Polish population: results of the PolSenior study. Arch Med Sci. 2017;13(5):1197-206. https://doi.org/10.5114/aoms.2015.55270

11. Andrade GN, Camacho ACLF, Assis CR, Queiroz RS. The pain in elderly caregivers: an integrative review. Rev Enferm Atual InDerme. 2019;87(25). https://doi.org/10.31011/reaid-2019-v.87-n.25-art.218

12. Tomey K, Greendale GA, Kravitz HM, Bromberger JT, Burns JW, Dugan AS, et al. Associations between aspects of pain and cognitive performance and the contribution of depressive symptoms in mid-life women: a cross-sectional analysis. Maturitas. 2015;80(1):106-12. https://doi.org/10.1016/j.maturitas.2014.10.013

13. van der Leeuw G, Eggermont LHP, Shi L, Milberg WP, Gross AL, Hausdorff JM, et al. Pain and cognitive function among older adults living in the community. J Gerontol A Biol Sci Med Sci. 2016;71(3):398-405. https://doi.org/10.1093/gerona/glv166

14. van der Leeuw G, Leveille SG, Dong Z, Shi L, Habtemariam D, Milberg W, et al. Chronic pain and attention in older community-dwelling adults. J Am Geriatr Soc. 2018;66(7):1318-24. https://doi.org/10.1111/jgs.15413

15. Whitlock EL, Diaz-Ramirez LG, Glymour MM, Boscardin WJ, Covinsky KE, Smith AK. Association between persistent pain and memory decline and dementia in a longitudinal cohort of elders. JAMA Intern Med. 2017;177(8):1146. https://doi.org/10.1001/jamainternmed.2017.1622

16. Moriarty $\mathrm{O}, \mathrm{McG}$ uire BE, Finn DP. The effect of pain on cognitive function: a review of clinical and preclinical research. Prog Neurobiol. 2011;93(3):385-404. https://doi.org/10.1016/j.pneurobio.2011.01.002

17. Simons LE, Elman I, Borsook D. Psychological processing in chronic pain: a neural systems approach. Neurosci Biobehav Rev. 2014;39:61-78. https://doi.org/10.1016/j.neubiorev.2013.12.006 
18. Legrain V, Damme S Van, Eccleston C, Davis KD, Seminowicz DA, Crombez G. A neurocognitive model of attention to pain: behavioral and neuroimaging evidence. Pain. 2009;144(3):230-2. https://doi.org/10.1016/j.pain.2009.03.020

19. Lino VTS, Pereira SEM, Camacho LAB, Ribeiro Filho ST, Buksman S. Adaptação transcultural da Escala de Independência em Atividades da Vida Diária (Escala de Katz). 2008;24(1):103-12. https://doi.org/10.1590/S0102-311X2008000100010

20. Santos RL, Virtuoso JS. Confiabilidade da versão da escala brasileira da escala de atividades instrumentais da vida diária. RBPS. 2008;21(4):290-6. https://doi.org/10.5020/575

21. Merskey H. Bogduk N. Classification of Chronic Pain [Internet]. 1994 [cited 2018 Jun 8]. Available from: https://www.iasp-pain.org/ PublicationsNews/Content.aspx?ItemNumber=1957\&navitemNumber $=677$

22. César K, Yassuda MS, Porto FHG, Brucki SMD, Nitrini R. Addenbrooke's cognitive examination-revised: normative and accuracy data for seniors with heterogeneous educational level in Brazil. Int Psychogeriatrics. 2017;29(08):1345-53. https://doi.org/10.1017/ S1041610217000734

23. Scazufca M. Brazilian version of the Burden Interview scale for the assessment of burden of care in carers of people with mental illnesses. Rev Bras Psiquiatr. 2002;24(1):12-7. https://doi.org/10.1590/S1516-44462002000100006

24. Almeida OP, Almeida SA. Confiabilidade da versão brasileira da escala de depressão em geriatria (GDS) versão reduzida. Arq Neuropsiquiatr. 1999;57:2. https://doi.org/10.1590/S0004-282X1999000300013

25. Luft CDB, Sanches SO, Mazo GZ, Andrade A. Versão brasileira da Escala de Estresse Percebido: tradução e validação para idosos. Rev Saude Publica. 2007;41(4):606-15. https://doi.org/10.1590/S0034-89102007000400015

26. Veronese N, Koyanagi A, Solmi M, Thompson T, Maggi S, Schofield P. et al. Pain is not associated with cognitive decline in older adults: a fouryear longitudinal study. Maturitas. 2018;115:92-6. https://doi.org/10.1016/j.maturitas.2018.07.001

27. Ojeda B, Dueñas M, Salazar A, Mico JA, Torres LM, Failde I. Factors influencing cognitive impairment in neuropathic and musculoskeletal pain and fibromyalgia. Pain Med. 2018;19(3):499-510. https://doi.org/10.1093/pm/pnx024

28. Oosterman JM, Vries K, Dijkerman HC, Haan EHF, Scherder EJA. Exploring the relationship between cognition and self-reported pain in residents of homes for the elderly. Int Psychogeriatrics. 2009;21(01):157. https://doi.org/10.1017/S1041610208007941

29. Oosterman JM, Gibson SJ, Pulles WLJA, Veldhuijzen DS. On the moderating role of age in the relationship between pain and cognition. Eur J Pain. 2013;17(5):735-41. https://doi.org/10.1002/j.1532-2149.2012.00235.x

30. Ribeiro LCC, Alves PB, Meira EP. Percepção dos idosos sobre as alterações fisiológicas do envelhecimento. Ciência. Cuid Saúde. 2009;8(2):220-7. https://doi.org/10.4025/cienccuidsaude.v8i2.8202

31. Yassuda MS, Lasca VB, Neri AL. Metamemory and self-efficacy: a validation study of research instruments in memory aging. Psicol Reflex Crít 2005;18(1):78-90. https://doi.org/10.1590/S0102-79722005000100011

32. Espírito-Santo H, Pena IT, Queiroz Garcia I, Freitas CP, Couto M, Daniel F. Memory and aging: what is the real impact of age?. Port J Behav Soc Res. 2016;41-54. https://doi.org/10.19234/ismt.rpics.2016.2.2.40

33. Foroni PM, Santos PL. Risk and protective factors associated with cognitive decline in aging-a systematic review of literature. Rev Bras Promoç Saúde. 2012;25(3):364-73. https://doi.org/10.5020/18061230.2012.p364

34. Geda YE, Knopman DS, Mrazek DA, Jicha GA, Smith GE, Negash S, et al. Depression, apolipoprotein e genotype, and the incidence of mild cognitive impairment: a prospective cohort study. Arch Neurol. 2006;63(3):435. https://doi.org/10.1001/archneur.63.3.435

35. Zwar L, König H-H, Hajek A. The impact of different types of informal caregiving on cognitive functioning of older caregivers: Evidence from a longitudinal. population-based study in Germany. Soc Sci Med. 2018;214:12-9. https://doi.org/10.1016/j.socscimed.2018.07.048

36. Vitaliano PP, Zhang J, Young HM, Caswell LW, Scanlan JM, Echeverria D. Depressed mood mediates decline in cognitive processing speed in caregivers. Gerontologist. 200;49(1):12-22. https://doi.org/10.1093/geront/gnp004 